\title{
Brand Loyalty in a Bertrand-Type Oligopoly Setting
}

\author{
Demetri Kantarelis \\ Grenon School of Business, Assumption College, Worcester, USA \\ Email:dkantar@assumption.edu
}

How to cite this paper: Kantarelis, D. (2019) Brand Loyalty in a Bertrand-Type Oligopoly Setting. American Journal of Industrial and Business Management, 9, 2250-2262.

https://doi.org/10.4236/ajibm.2019.912149

Received: November 27, 2019

Accepted: December 21, 2019

Published: December 24, 2019

Copyright $\odot 2019$ by author(s) and Scientific Research Publishing Inc. This work is licensed under the Creative Commons Attribution International License (CC BY 4.0).

http://creativecommons.org/licenses/by/4.0/

\section{(c) (i) Open Access}

\begin{abstract}
It appears that in today's brand-proliferating, constantly market-segmenting and technologically evolving global economy, consumer perceptions affect an entire industry in which brand loyalty is possible such as the extremely hot and rapidly developing global smartphone industry. In a brand-loyalty-prone industry, what are the implications of brand loyalty in terms of, among others, industry price, sales and profit? I propose a market structure in which each firm's profit depends on sales of a brand realized in a captive market segment as well as on sales of the same brand realized in a non-captive market segment; ignoring costs of production and assuming that all firms simultaneously enter into the two market segments and that price discrimination of the $3^{\text {rd }}$ degree is not possible, I employ a Bertrand-type duopoly structure and then aggregate over $\mathrm{n}$ firms. Counterintuitively, industry price, quantity and profit all rise with entry. The findings are primarily due to the assumed entry condition (that each entrant enters into two market segments one of which is a monopoly) and secondarily to the inability of the sellers to price discriminate. I conclude that experience-type data in the smartphone industry can be considered as somewhat supportive of the proposed structure and the derived theoretical results.
\end{abstract}

\section{Keywords}

Brand Loyalty, Bertrand-Type Oligopoly, Smartphone Industry, Market Segmentation

\section{Introduction: Literature Review, Motivation and Market Structure Setting}

In the last two years or so numerous published papers, especially in marketing and management outlets, deal with brand loyalty ranging from conceptual to empirical and from specific to general. All recommend that brand loyalty ought 
to be pursued by firms because it contributes, at least for a while, to higher profit. In the field of industrial organization though, especially in the sub-field of market structures, brand loyalty has not been incorporated into formal modelling; researchers in this field are complacent with location-type oligopoly models subject to Nash mentality (more details in Kantarelis (2020) [1], chapters 3 and 4).

As we march through the $4^{\text {th }}$ industrial revolution, firms appear to rely more on brand loyalty through various business models, strategies and tactics. As pointed-out by Tartaglione et al. (2019) [2], brand loyalty (how consumers perceive a brand) is one of the hottest topics in marketing and management today because loyal consumers are more profitable due to price insensitivity, lower needs for service, and high degree of repurchasing. Cachon (2019) [3] reasons that as a reaction to the way people live today, that is in an ocean of new technologies and information resources, innovations in new business models and strategies (for example, sharing economy models, or a never discount strategy), enable firms to create novelty and as a result more or less sustainable brand loyalty. Rutz et al. (2019) [4] focus on monetizing user engagement via in-app advertising and explain how publishers, when trying to monetize engagement of an app in a mobile platform beyond the initial download, can generate forecasts used as tools to identify with pinpoint accuracy potentially loyal consumers. Similarly, Sayedi (2018) [5] states that real-time bidding permits promoters to target clients at an individual level by tracking their website surfing activity thorough cookies information; hence, advertisers can customize their ads for potentially loyal clients. Yoganarasimhan (2019) [6], enlightens us how machine-learning (with data from query-based past search by a firm's potential buyers on the firm's webpage) can lead to customer personalization as a function of user history and query type, leading to better understanding of consumer needs and their classification into more or less loyal patrons. Haddad et al. (2019) [7], discuss startups (specifically, new firms with the purpose of reinventing financial technology) and they point out the importance of loyalty programs offered by such entities such as rewards for brand loyalty or giving customers advanced access to new products, special sales coupons, or free merchandise. Suchánek et al. (2019) [8], concerned with creation of consumer loyalty, clarify that purchasing implies more familiarity with the product making matching quality expectations with satisfaction a fundamental ingredient for the establishing and maintaining of loyalty. Zhang (2019) [9], points out the importance of five consumption experiences on brand loyalty (sensory, emotional, thinking, action and related) incorporation of which in business model contributes to higher profit. Molinillo et al. (2018) [10], have succeeded in measuring brand success, across different product categories, based on four critical constructs: equity, trust, satisfaction and loyalty; among other results, they report that brand loyalty is positively affected by brand trust and brand satisfaction; they recommend that their Consumer-Based Brand Performance Model would be useful as a tool in tracking brand performance and for comparison vis-à-vis 
other brands. Garg et al. (2019) [11], advocate that for effective consumer segmentation, more sales and higher profits, we need to think in terms of factors that influence brand love (such as reputation, anthropomorphisation and communal orientation) and indicators of brand love (such as word of mouth, consumer forgiveness, and willingness to pay higher prices). Concerned with the evolution of brand loyalty, Casteran et al. (2019) [12], find, among other, that although on aggregate and through time (over 54 categories and 6 years in Denmark) brand loyalty drops, significant decline was observed only for a small number of categories.

It appears that in today's brand-proliferating, constantly market-segmenting and technologically evolving global economy, consumer perceptions affect an entire industry in which brand loyalty is possible such as the extremely hot and rapidly developing global smartphone industry. In the paragraphs that follow, motivated by the arguments and findings of the above-mentioned researchers, I would like to address the following questions: In a brand-loyalty-prone industry, what are the implications of brand loyalty in terms of, among other, industry price, sales and profit? Can a theoretical market-structure-type model be constructed to include some of the key features implied above and would the model's assertions find empirical support?

A brand seller may encounter two types of consumers: loyal (captive) buyers and peripheral (non-captive) buyers. Loyal buyers are hard-core patrons who purchase the brand no matter what; consumer brand loyalty offers monopoly power to the seller because the buyer of a brand is blind to substitute brands in the market even though substitute brands may be less expensive, exhibit higher quality and/or deliver better service. Peripheral buyers, on the other hand, make markets competitive: they may like simultaneously several brands, develop the desire to move from consuming one brand to another and/or look for deals.

Understandably, brand loyalty ought to be pursued for it may contribute to profit due to barriers to entry because of competitive advantage, potential for additional market share, client acceptance of product alterations and willingness to pay higher prices relative to less expensive substitutes, as well as lower cost to serve existing clients. As Dimitroff (2018) [13] states, "[e]xtreme loyalists keep buying their brands products even when they are ... over-priced."

Of course, a brand may not turn all clients into loyal cult-like followers; some potential customers would choose to consider competing brands. Hence, a firm may find itself selling a brand, simultaneously, in a monopoly market (consisting of loyal-type or captive buyers) and a competitive market (consisting of peripheral-type or non-captive buyers). Consider for example some brands monitored by BankMyCell (2019) [14] which looked at data from 64,273 smartphone users to determine what percentage of users trading in their phones remained loyal to their current brand; as reported (bullets added),

- Apple had $74.6 \%$ iPhone trade-in brand loyalty, with $12.8 \%$ heading to Samsung, $5.3 \%$ to $L G$.

- Samsung had 63.9\% Galaxy trade-in brand loyalty, with 17\% heading to Ap- 
ple, $8 \%$ to $L G$.

- Google had 51.0\% trade-in brand loyalty, with the lowest volume heading to Apple at $10.1 \%$.

- LG, Motorola and HTC all fell below $41 \%$ brand loyalty at trade-in.

- Only $10.8 \%$ of HTC respondents stayed loyal, with $32.1 \%$ heading to Samsung, $17.1 \%$ to Apple.

The percentages reported by BankMyCell may be considered quantitative approximations of brand captives (74.6\% for iPhone and $63.9 \%$ for Galaxy) and therefore of brand non-captives (25.4\% for iPhone and $36.1 \%$ for Galaxy); similarly, for the rest of the brands in the report. I consider this reality to be justification for each brand seller to consider, simultaneously and indiscriminately, two markets: the captive and the non-captive.

In this paper, building on past work by Kantarelis (1994) [15], I would like to make an attempt to describe a market structure in which each firm's profit depends on sales of a brand realized in its captive market $\left(S_{C}\right)$ as well as on sales of the same brand realized in its non-captive market $\left(S_{N C}\right)$; ignoring costs of production (justification later), the profit function of firm $i$ may be stated as follows: $\pi_{i}\left(S_{C i}, S_{N C i}\right)$ where $\pi=$ Profit, $S=$ Sales, $C=$ Captive, and $N C=$ Non-Captive. In turn, assuming that all firms are identical price competitors and that price discrimination of the $3^{\text {rd }}$ degree is not possible, I aggregate over $\mathrm{n}$ firms and discuss some theoretical results. This paper differs from previous work in that it simplifies and better explains matters and as such, I believe, it serves as a more effective pedagogical tool.

In whatever follows, I describe a duopoly setting in Section 2. In Section 3, I aggregate over $\mathrm{n}$ firms and discuss entry implications. In Section 4, I describe some real-world brand loyalty cases followed by conclusion and summary in Section 5 .

\section{Linear Duopoly Setting}

Consider price competing firms ( $i$ and $j$ ) that experience zero costs. Let $P=$ market price, $Q=$ quantity, and coefficients $(\alpha, \beta, \gamma, \delta, \varepsilon)=$ real positive numbers. Sales in the $\mathrm{C}$ market segment may be expressed as

$$
S_{C i}=P_{i} Q_{C i}=P_{i}\left(\alpha-\beta P_{i}\right) \text {. }
$$

Sales in the NC segment may be expressed as

$$
S_{N C i}=P_{i} Q_{N C i}=P_{i}(1 / n)\left[\gamma-\delta P_{i}+(n-1) \varepsilon P_{j}\right] \text {. }
$$

when $n=1$, the firm acts as a monopolist in both $\mathrm{C}$ and $\mathrm{NC}$ market segments. In a duopoly market structure, with $n=2$, firms are assumed to follow a Bertrand-type mentality (for more details see Kantrarelis (2020) [1], pp. 96-102): each maximizes profit subject to the condition that the rival does not alter price. In Equation (2), the term $(1 / n)$ indicates that access to the market is split evenly but, because coefficients $\delta$ and $\varepsilon$ may be unequal, firms' market shares may differ. (For other reasons, multiplication of $(2)$ by $(1 / n)$ was originally proposed by Ro- 
senthal (1980) [16]). In turn, is profit may be expressed as the summation of (1) and (2), or

$$
\pi_{i}=S_{C i}+S_{N C i}=\left\{\alpha+(1 / n)\left[\gamma+(n-1) \varepsilon P_{j}\right]\right\} P_{i}-[\beta+(1 / n) \delta] P_{i}^{2}
$$

and, similarly, $j$ s profit may be expressed as

$$
\pi_{j}=S_{C j}+S_{N C j}=\left\{\alpha+(1 / n)\left[\gamma+(n-1) \varepsilon P_{i}\right]\right\} P_{j}-[\beta+(1 / n) \delta] P_{j}^{2} .
$$

Assuming, as Bertrand requires, that the rival's price remains constant, each duopolist may maximize profit with respect to its own price. Partially differentiating (3) with respect to $P_{i}$ and (4) with respect to $P_{j}$ and setting equal to zero and then solving for their respective prices, firms derive their best response function (BRF) as follows:

$$
\begin{aligned}
& \vartheta \pi_{i} \mid \vartheta P_{i}=\alpha+(1 / n)\left[\gamma+(n-1) \varepsilon P_{j}\right]-2[\beta+(1 / n) \delta] P_{i}=0 \\
& \rightarrow P_{i}=\left\{\alpha+(1 / n)\left[\gamma+(n-1) \varepsilon P_{j}\right]\right\} \mid 2[\beta+(1 / n) \delta] \\
& \vartheta \pi_{j} \mid \vartheta P_{j}=\alpha+(1 / n)\left[\gamma+(n-1) \varepsilon P_{i}\right]-2[\beta+(1 / n) \delta] P_{j}=0 \\
& \rightarrow P_{j}=\left\{\alpha+(1 / n)\left[\gamma+(n-1) \varepsilon P_{i}\right]\right\} \mid 2[\beta+(1 / n) \delta]
\end{aligned}
$$

Letting $\alpha=100, \beta=0.5, \gamma=60, \delta=1.5$, and $\varepsilon=1.5$, the duopolists' best response and iso-profit functions, are graphed in Figure 1. The equilibrium solution (identical to a Nash equilibrium) may be found by solving simultaneously the linear system of the two response functions (5) and (6) for $P_{i}$ and $P_{j}$. For the chosen parameter values, this equilibrium is $(74.286,74.286)$ and is identified with point e.

Figure 2, enables one to compare the equilibrium of the proposed model (e) to the one of the traditional Bertrand (e) according to which, with the same parameter symbols and numerical values as those utilized in the proposed NC market and excluding cost, profit is

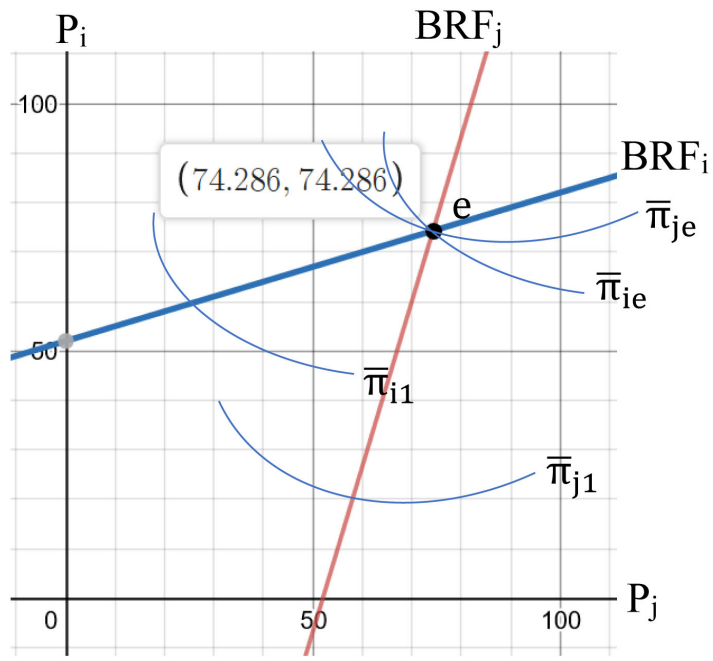

Figure 1. Best Response Functions (BRF) and Iso-Profit Functions $(\bar{\pi})$ where, at equilibrium (e), $\bar{\pi}_{e}>\bar{\pi}_{1}$. 


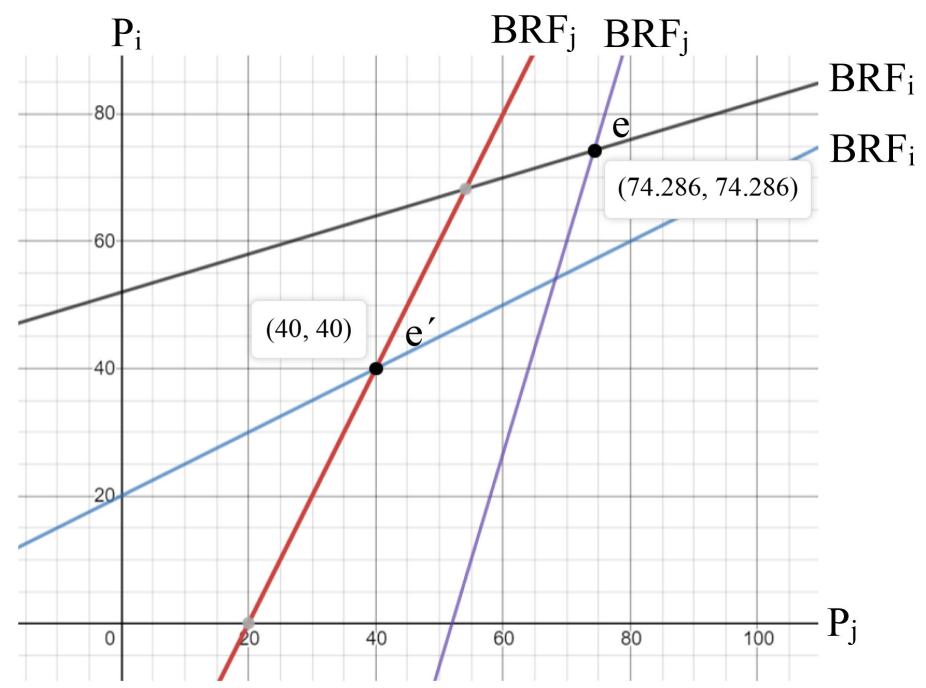

Figure 2. Equilibrium in the recommended model (e) and in the traditional Bertrand (e).

$\pi_{i}=P_{i} Q_{i}=P_{i}\left(\gamma-\delta P_{i}+\varepsilon P_{j}\right)=P_{i}\left(60-1.5 P_{i}+1.5 P_{j}\right)$. Obviously, $\mathrm{e}^{\prime}$ corresponds to lower prices and profit primarily because brand product monopoly-type gains, due the additional captive market segment, are not allowed in the traditional Bertrand model.

\section{Entry and Aggregation}

Suppose a firm enters an industry with its own brand product and it successfully establishes a captive (monopoly) market. Let all entering firms do the same; therefore, $\mathrm{n}$ firms would create $\mathrm{n}$ captive (monopoly) markets.

Additionally, let all entering firms have access to an $\mathrm{n}$-firm competitive market in which they sell the same brand products as those they sell in their captive markets. Hence, in this hypothetical industry (which combines both a monopoly market segment and a competitive one-with no possible price discrimination), each entrant is assumed to be able to sell the same brand, simultaneously to two markets: its loyal market and in the market where it experiences competition from other brands. The primary question I would like to address here is, given this industry setting and the entry conditions as described above, what would be the aggregate impact of entry on industry price, quantity and profit?

For aggregation purposes, I would like to expand upon the duopoly results established above, since, conveniently " $n$ " has been pre-inserted in the profit functions. For equilibrium in the $\mathrm{n}$-firm case, I assume that $P_{i}=P_{j}=P_{e}$. Thus, from (5) or (6),

$$
\begin{aligned}
& P_{e}=\left\{\alpha+(1 / n)\left[\gamma+(n-1) \varepsilon P_{e}\right]\right\} \mid 2[\beta+(1 / n) \delta] \\
& \rightarrow P_{e}=[\alpha+(1 / n) \gamma] \mid\{2[\beta+(1 / n) \delta]-(1 / n)(n-1) \varepsilon\}
\end{aligned}
$$

Therefore, from $i$ s captive demand function and (7), $Q_{C i}=\alpha-\beta P_{e}$. Since all firms are identical in terms of each having a captive market segment, then from all $\mathrm{n}$ monopolies, 


$$
Q_{C e}=n Q_{C i}=n\left(\alpha-\beta P_{e}\right) .
$$

From $i$ s non-captive market demand function and (7), $Q_{N C i}=(1 / n)\left[\gamma-\delta P_{e}+(n-1) \varepsilon P_{e}\right]$. Since all firms meet in this market segment,

$$
Q_{N C e}=n Q_{N C i}=n(1 / n)\left[\gamma-\delta P_{e}+(n-1) \varepsilon P_{e}\right]=\gamma-[\delta-(n-1) \varepsilon] P_{e} .
$$

Therefore, aggregate industry quantity $\left(Q_{A}\right)$ and profit $\left(\Pi_{A}\right)$ are, respectively,

$$
Q_{A}=Q_{C e}+Q_{N C e}=(n \alpha+\gamma)-[n \beta+\delta-(n-1) \varepsilon] P_{e}
$$

and

$$
\Pi_{A}=Q_{A} P_{e} .
$$

Table 1 exhibits a numerical example with $\alpha=\gamma=100$ and $\beta=\delta=\varepsilon=1$ followed by three graphs based on the numerical example: Figure 3 ( $P_{e}$ versus $n$ ), Figure $4\left(Q_{A}\right.$ versus $\left.n\right)$, and Figure $5\left(\Pi_{A}\right.$ versus $\left.n\right)$. As the numerical example and the corresponding graphs show, Pe rises with $n$ in a diminishing fashion whereas $Q_{A}$ and $\Pi_{A}$ rise with $n$ exponentially. Numerical examples with different parameter values generated similar results; in some of these examples, when both $\delta$ and $\varepsilon$ were assigned numerical values larger than 1, with all else unchanged, higher positive prices were generated up to a higher value of $n$ beyond which additional entry caused price to sharply drop below zero to rise thereafter with $n$, in a wave-like fashion approximately resembling the graph of a sawtooth wave function or a function such as this one: $y=1.1 \cos [x+(\pi / 2)-y]$.

In traditional Bertrand-type oligopoly models, entry of firms causes aggregate industry quantity $\left(Q_{A}\right)$ to rise and market prices $\left(P_{e}\right)$ along with aggregate profits $\left(\Pi_{A}\right)$ to fall. Counterintuitively, in the segmented market structure described here, $P_{e}, Q_{A}$, and $\Pi_{A}$ all rise with $n$, the number of entrants. These results may be

Table 1. Numerical example with $\alpha=\gamma=100$ and $\beta=\delta=\varepsilon=1$.

\begin{tabular}{cccc}
\hline $\boldsymbol{n}$ & $\boldsymbol{P}_{\boldsymbol{e}}$ & $\boldsymbol{Q A}$ & $\Pi \boldsymbol{A}$ \\
\hline 1 & 50.00 & 100.00 & 5000.00 \\
2 & 60.00 & 180.00 & $10,800.00$ \\
3 & 66.67 & 266.67 & $17,777.78$ \\
4 & 71.43 & 357.14 & $25,510.20$ \\
5 & 75.00 & 450.00 & $33,750.00$ \\
6 & 77.78 & 544.44 & $42,345.68$ \\
7 & 80.00 & 640.00 & $51,200.00$ \\
8 & 81.82 & 736.36 & $60,247.93$ \\
9 & 83.33 & 833.33 & $69,444.44$ \\
10 & 84.62 & 930.77 & $78,757.40$ \\
20 & 91.30 & 1917.39 & $175,066.16$ \\
40 & 95.35 & 3909.30 & $372,747.43$ \\
80 & 97.59 & 7904.82 & $771,434.17$
\end{tabular}




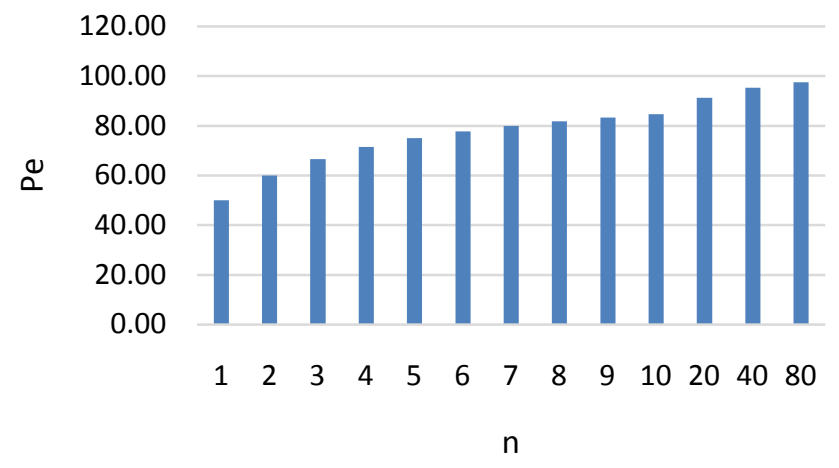

Figure 3. $P_{e}$ versus $n$.

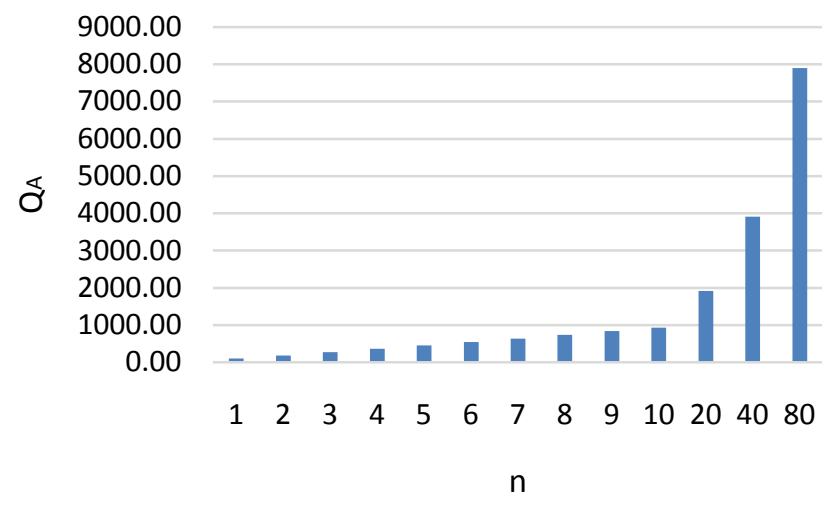

Figure 4. $Q_{A}$ versus $n$.

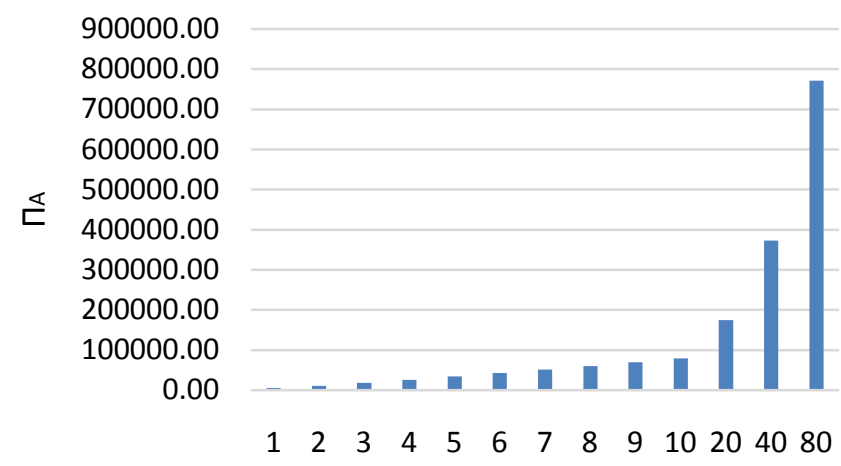

$\mathrm{n}$

Figure $5 . \Pi_{A}$ versus $n$.

considered reasonable since the proposed market structure consists of n monopolies selling to the segment of their obsessive or loyal shoppers and to a competitive market segment in which they all meet and compete without the opportunity to price discriminate: if most buyers are loyal, they would not object to higher prices, the same prices firms also charge to those few who are less loyal.

\section{The Proposed Model vis-à-vis the Global Smartphone Industry}

Brand loyalty examples abound; e.g., Coca-Cola, iPhone, IKEA, Nike, and many 
more. Although it sounds reasonable to assume that they sell, at the same price, to both loyal and non-loyal market segments and that entrants enter the way it was described above, perhaps none of the respective industries can readily offer data in support of the proposed unusual model. However, although the model may have some value as intellectual play its corroboration by experience-type data would be the ultimate test of its value.

It appears that brand-type market structures, resembling the proposed one, are highly concentrated with the top firms selling brands at high prices experiencing both higher sales and profit regardless of costs. Consider for instance a typical such industry that in the last 25 years we have all become so involved with and so dependent on, the smartphone industry. I would like to report below on how approximations to $n, P_{e}, Q_{A}$, and $\Pi_{A}$ (the industry's number of competitors, price as well as sales and profits) evolve through time.

- Regarding the number of competitors and growth, according to Holst (2019) [17], "the smartphone industry has been steadily developing and growing since then, both in market size, as well as in models and suppliers"; and according to Khandelwal, Rekha (2019) [18],

The global smartphone industry is huge and is growing rapidly. According to GSMA Intelligence, $80 \%$ of mobile connections globally will be smartphones by 2025. Currently, China, India, and the US are the top three countries by number of smartphone connections. Though there's a large number of smartphone companies, a few top players dominate the global smartphone industry ... Samsung, Huawei, Apple (AAPL), Xiaomi, Vivo, and Oppo control more than 75\% of the global smartphone market. According to Gartner, five of these companies (excluding Vivo) account for around 63\% of global smartphone sales. Four of the top six smartphone companies are Chinese.

- Regarding market prices, according to Holst (2019) [17], "in 2016, smartphones were sold at an average price of 282 U.S. dollars worldwide ... projected to rise to 317 U.S. dollars in 2021" and according to Kastrenakes (2019) [19],

[ $p]$ hones are more expensive than ever. Flagship devices from Apple, Samsung, Google, and other top manufacturers can now cost hundreds of dollars more than they did just a couple of years ago. Now, with the arrival of foldable phones, which are being priced at $\$ 2000$ and above, it looks like the upper limit for phone prices is going to keep growing.

- Regarding sales, the number of smartphones sold to end users worldwide went from about 122 million units in 2007, to a 970 in 2013. According to Protocol Digital Marketing (2019) [20],

[i] $n$ 2016, the number of smartphones sold to consumers stood at around 1.5 billion units, a significant increase from the 680 million units sold in 2012. This means that over 28 percent of the world s total population owned a smart device in 2016, a figure that is expected to increase to 37 percent by 2020. In the same year smartphone penetration is set to reach 60.5 percent in North America as well as in Western Europe. 
- Regarding profit, according to Gadgets Now (2018) [21], there are 6 increasingly profitable smartphone firms in the industry ranked from high to low as follows: Apple, Samsung, Huawei, Oppo, Vivo, and Xiaomi. In more detail (table format added),

\begin{tabular}{|c|c|}
\hline 1. Apple & $\begin{array}{l}\text { [It] continued to command lion's share of mobile handset industry's profits, } \\
\text { capturing almost } 60 \% \text { share. However, the company's profit is down from } 86 \% \text { in the } \\
\text { same quarter last year when Samsung had to gulp up a loss due to the Galaxy Note } 7 \\
\text { debacle. According to Counterpoint's research director, Neil Shah, Apple still } \\
\text { generates more than } \$ 150 \text { profit per iPhone sold and this will continue to grow into } \\
\text { the holiday season quarter, buoyed by the high-price iPhone X series. }\end{array}$ \\
\hline 2. Samsung & $\begin{array}{l}\text { [It] made a strong come back in the third quarter of this year with its Note } 8 \text { series, } \\
\text { while Galaxy } S 8 \text { series too continued to perform on par. The profit share reached } 26 \% \\
\text { as compared to its loss during the third quarter of } 2016 \text { due to Samsung Galaxy Note } \\
7 \text { recall. The South Korean company, courtesy relatively stronger demand for Note } 8 \\
\text { and mid-tier J series smartphones, have been able to capture almost a fourth of the } \\
\text { global mobile handset industry profits. }\end{array}$ \\
\hline 3. Huawei & $\begin{array}{l}\text { [It] witnessed highest profit growth of } 67 \% \text { YoY in Q3 } 2017 \text { due to its portfolio } \\
\text { expansion across price bands. Huawei s smartphone ASP grew by } 6 \% \text { YoY driven by } \\
\text { its Mate and P series. The company's per unit profit is } \$ 15 .\end{array}$ \\
\hline 4. Oppo & $\begin{array}{l}\text { [It] captured the fourth spot in global handset profit share, mainly driven by its } \\
\text { performance in China. Oppo's per unit profit is } \$ 14 \text {. }\end{array}$ \\
\hline 5. Vivo & $\begin{array}{l}\text { The company too owes its position to the strong performance in China. Vivo's per } \\
\text { unit profit is } \$ 13 \text {. }\end{array}$ \\
\hline 6. Xiaomi & $\begin{array}{l}\text { While Xiaomi has made a strong comeback with handset profit growth of } 41 \% \text { YoY, it } \\
\text { is still behind the market leaders. For Xiaomi, offline distribution is the key to } \\
\text { reaching Oppo or Huawei s scale, but most of Xiaomis sales are still skewed towards } \\
\text { lower-end models. Xiaomi needs premium flagship like Mi Mix } 2 \text { or Mi } 6 \text { series to } \\
\text { scale and drive higher profits to offset the offline expansion costs. Xiaomis per unit } \\
\text { profit is lower (\$2) as it plays on very thin margins. }\end{array}$ \\
\hline
\end{tabular}

Does "experience" in the smartphone industry confirm the theoretical conclusions of the proposed market structure model? To some extent, yes:

1) The entire industry is growing with sales and suppliers since more of them enter (it is relatively inexpensive and easy to manufacture a smartphone today) than exit. Thus, $Q_{A}$ and $n$ are both rising.

2) Prices have been rising over time-only lately to diminish a bit. Thus, on average, $P_{e}$ is rising.

3) Profits of the top 6 firms are rising which, combined with more entry than exit, causes overall industry profits to improve. Thus, on average, $\Pi_{A}$ is rising as well.

Of course, the experience-type evidence provided here should be taken with a grain of salt; it ought to be considered as somewhat supportive of the proposed structure. Undoubtedly, to test the theoretical predictions of the model a rigorous empirical model is needed such as the one utilized by Fan and Yang (2019) [22] in their seminal paper. 


\section{Summary and Conclusion}

I proposed above a market structure in which each firm's profit depends on sales of a brand realized in its captive market $\left(S_{C}\right)$ as well as on sales of the same brand realized in its non-captive market $\left(S_{N C}\right)$; ignoring costs of production, the profit function of firm $i$ was stated as follows: $\pi_{i}\left(S_{C D} S_{N C i}\right)$. In turn, assuming that all firms simultaneously enter into two market segments (their loyal or captive market and their non-loyal or competitive market) and that price discrimination of the $3^{\text {rd }}$ degree is not possible, I employed a Bertrand-type duopoly structure and then aggregated over $\mathrm{n}$ firms to determine, counterintuitively, that industry price, quantity and profit all rise with entry. The findings are primarily due to the assumed entry condition (that each entrant enters into two market segments one of which is a monopoly) and secondarily to the inability of the sellers to price discriminate. It was reported that "experience" in the smartphone industry can be considered as somewhat supportive but not as confirming of the proposed structure and the derived theoretical results.

In conclusion, there are many elements missing from the proposed model inclusion of which, in future research, would make it both more general and realistic. More specifically, as stated above, cost was not allowed to enter the model. Costs of some firms are very low due to direct sales (as practiced by Xiaomi and OnePlus) which of course contribute to consumer price insensitivity. In general, judging from market experience with most smartphone industry firms, it appears that cost does not play a significant role in the competition process since sellers routinely overcharge without loss of sales despite the fact that the rate of sales is diminishing in the last 2 or 3 years indicating that consumers are becoming more sensitive to continually rising prices, increasingly opting to keep their cellphones longer.

Another missing fact from the above model is that global markets are dominated by a small number of leading firms (like the six smartphone companies reported above) each offering numerous, more or less successful, brand versions. Perhaps a leadership-type oligopoly model with each seller offering many products would better represent reality. Additionally, a model in which sellers sell in many markets (not only two) with each market experiencing various degrees of competition would shed more light. Moreover, a more realistic model, especially as it applies to cellphones, ought to build in the fact that conventions in some countries differ in relation to governmental regulations, bundling, and cross-country functionality.

Finally, instead of assuming linear demand functions (derived from a general utility function), it may be fruitful to derive more suitable demand functions from specific utility models that better represent industries under consideration. In the smartphone industry, given the abundant applications, different market (country) conventions and the technical peculiarities as well as uncertainties associated with quality, the work of Fan and Yang (2019) [22], as delineated in section 3 of their paper, could offer useful guidance along these lines. 


\section{Conflicts of Interest}

The author declares no conflicts of interest regarding the publication of this paper.

\section{References}

[1] Kantarelis, D. (2020) Theories of the Firm. 6th Edition, Inderscience, Geneva, 96-102.

[2] Tartaglione, A.M., Cavacece, Y., Russo, G. and Granata, G. (2019) A Systematic Mapping Study on Customer Loyalty and Brand Management. Administrative Sciences, 9, 1-21. https://doi.org/10.3390/admsci9010008

[3] Cachon, G.P. (2018) A Research Framework for Business Models: What Is Common among Fast Fashion, E-Tailing, and Ride Sharing? Management Science (Articles in Advance). https://doi.org/10.2139/ssrn.3250441

[4] Oliver, R., Aravindakshan, A. and Rubel, O. (2019) Measuring and Forecasting Mobile Game App Engagement. International Journal of Research in Marketing, 36, 185-199. https://doi.org/10.1016/j.ijresmar.2019.01.002

[5] Sayedi, A. (2018) Real-Time Bidding in Online Display Advertising. Marketing Science, 37, 507-684. https://doi.org/10.1287/mksc.2017.1083

[6] Yoganarasimhan, H. (2019) Search Personalization Using Machine Learning. Management Science (Articles in Advance). https://doi.org/10.1287/mnsc.2018.3255

[7] Haddad, C. and Hornuf, L. (2019) The Emergence of the Global Fintech Market: Economic and Technological Determinants. Small Business Economics, 53, 81-105. https://doi.org/10.1007/s11187-018-9991-x

[8] Suchánek, P. and Králová, M. (2019) Customer Satisfaction, Loyalty, Knowledge and Competitiveness in the Food Industry. Economic Research-Ekonomska Istraivanja, 32, 1237-1255. https://doi.org/10.1080/1331677X.2019.1627893

[9] Zhang, X. (2019) Research on the Influence Factors of Brand Experience on Consumers Brand Loyalty. Open Journal of Business and Management, 7, 556-561. https://doi.org/10.4236/ojbm.2019.72038

[10] Molinillo, S., Ekinci, Y. and Japutra, A. (2018) A Consumer-Based Brand Performance Model for Assessing Brand Success. International Journal of Market Research, 61, 93-110. https://doi.org/10.1177/1470785318762990

[11] Garg, R., Mukherjee, J. and Biswas, S. (2019) Consumer-Based Determinants of Brand Love and Its Consequences: A Quantitative Research. International Journal of Business and Emerging Markets, 11, 122-143. https://doi.org/10.1504/IJBEM.2019.10022495

[12] Gauthier, C., Chrysochou, P. and Meyer-Waarden, L. (2019) Brand Loyalty Evolution and the Impact of Category Characteristics. Marketing Letters, 30, 57-73. https://doi.org/10.1007/s11002-019-09484-w

[13] Dimitroff, V. (2018) When Has Extreme Loyalty Ever Paid Off? https://www.quora.com/When-has-extreme-loyalty-ever-paid-off?top_ans=8573119 4

[14] BankMyCell (2019). https://www.bankmycell.com/blog/smartphone-brand-loyalty-during-trade-in-2019

[15] Kantarelis, D. (1994) Captive and Common Markets without Price Discrimination. In: Amin, S.G., Barr, P.B. and Moore, D.L., Eds., World Business Trends, Academy of Business Administration, Wembley, 279-286. 
[16] Rosenthal, R.W. (1980) A Model in Which an Increase in the Number of Sellers Leads to a Higher Price. Econometrica, 48, 1575-1579.

https://doi.org/10.2307/1912828

[17] Holst, A. (2019). https://www.statista.com

[18] Khandelwal, R. (2019) Global Smartphone Companies: An Overview. https://marketrealist.com/2019/09/global-smartphone-companies-an-overview

[19] Kastrenakes, J. (2019) How Phones Went from $\$ 200$ to $\$ 2,000$. https://www.theverge.com/2019/3/18/18263584/why-phones-are-so-expensive-price -apple-samsung-google

[20] Protocol Digital Marketing (2019). https://www.protocol.gr/number-of-smartphones-sold-to-end-users-worldwide-fro m-2007-to-2018

[21] Gadgets Now (2018). https://www.gadgetsnow.com/slideshows/ranked-worlds-6-most-profitable-smartp hone-companies/Sixth-Xiaomi/photolist/62273542.cms

[22] Fan, Y. and Yang, C.Y. (2019) Competition, Product Proliferation and Welfare: A Study of the US Smartphone Market. 